\title{
SPATIAL DIFFUSION OF ECONOMIC IMPACTS AND DEVELOPMENT BENEFITS IN HIERARCHICALLY STRUCTURED TRADE REGIONS: AN EMPIRICAL APPLICATION OF CENTRAL PLACE-BASED INPUT-OUTPUT ANALYSIS
}

\author{
M.H. Robison, J.R. Hamilton, K.P. Connaughton, \\ N. Meyer, and R. Coupal*
}

\begin{abstract}
This paper examines the spatial diffusion of economic effects from rural to urban subregions. By employing a spatial variation of the supply-demand-pool nonsurvey I-O modeling technique and central place theory, we can construct an interregional I-O model for a functional economic trade region centered on Salt Lake City, Utah. Rural to urban spillovers are explored with summary measures of interconnectedness. It is found that the diffusion of economic effects from lower- to higher-order subregions depends on the infrastructure development of lower-order subregions and on the infrastructure development of intervening subregions. The modeling framework adds a spatial dimension that can enhance the effectiveness of economic impact assessment and economic development policy formation.
\end{abstract}

\section{INTRODUCTION}

Information on the internal structure of regions is a key ingredient in the formation of economic development policy, and regional input-output (I-O) is an important source for much of this information. Yet regional I-O applications often fall short of policymaker expectations. Information generally is lacking on the spatial structure of regions, particularly the features of the regional economy that condition the spatial diffusion of economic impacts and economic development benefits.

This paper focuses on the spatial diffusion of economic effects in the form of spillovers from rural to urban subregions. We construct an interregional I-O model for a functional economic trade region centered on Salt Lake City, Utah. Central place theory guides our definition of subregions and our assumptions regarding the structure of interregional trade. Given our focus on rural to urban spillovers, we find it useful to assume strictly hierarchical trade, i.e., a rigid Christaller-like one-way trade structure where goods flow down but never up the trade

\footnotetext{
*Assistant Professor and Professor, University of Idaho; Research Forester, U.S.D.A. Forest Service Pacific Northwest Research Station; Research Professor and Research Associate, University of Idaho, respectively.
} 
hierarchy. We recognize the limitations of this assumption, and we otherwise discuss its implications in a dedicated section later in the paper.

Central place theory (Christaller 1966; Lösch 1938) explains the spatial structure of trade within regions. Regional I-O analysis (Isard 1951) focuses on the interindustry structure of trade within and between regions and on regional economic impact assessment. Mulligan (1979) demonstrated a kinship between central place theory and regional I-O. Inspired by Mulligan's work, Robison and Miller (1991) constructed the first empirical central-place-based I-O model, an intercommunity I-O model of a rural region in southwest Idaho.

The economic models constructed in this paper focus on a set of mixed rural and urban functional economic subregions (Fox and Kumar 1965) and build on the existing central place and regional I-O literature. We explore rural to urban spillovers with summary measures of interconnectedness proposed by Hamilton and Jensen (1983), positing the determinants of interconnectedness predicted by central place theory and then testing them against measures favored by the interregional I-O analyst. Our comparison sheds light on features of the regional economy that determine the impact of rural development on the economies of urban places. We conclude by considering general implications of our empirical exercise for economic impact assessment and economic development policy.

\section{CENTRAL PLACE THEORY}

Central place theory views the regional landscape with subregions defined and ordered according to the goods and services they provide to themselves and to other subregions (Berry et al. 1988). Parr (1987) provides a taxonomy of goods and services in a central place hierarchy, distinguishing between "central place" and "specialized" goods and services. "Central place goods and services" include items for which there is essentially ubiquitous demand: groceries, consumer durables, movies, air travel, accounting, legal and business services, and so on. "Specialized goods and services" are items for which production is unique to particular regions: agricultural products, timber, input-oriented manufacturing, military installations, federal govermment offices, and so on.

Lower-order subregions supply their own lower-order central place goods and services and obtain higher-order central place goods and services from higher-order subregions. Higher-order subregions supply their own lower- and higher-order central place goods and services. There is no trade in central place goods and services between same-order subregions. Subregions at the bottom of the trade hierarchy-lowest-order subregions-derive their income from the export of specialized goods to other subregions for processing or outside the larger 
region. Higher-order subregions derive their income from the supply of higherorder central place goods and services to lower-order subregions and from the export of specialized goods to other subregions and to outside the larger region.

\section{IMPLICATIONS OF ASSUMING STRICTLY HIERARCHICAL TRADE}

Christaller (1966) deduced a hierarchy of settlements, i.e., size and placement, given assumptions regarding the production and supply of central place goods. Christaller's hierarchy appears rigid, with goods flowing one way-down but never up the trade hierarchy (Seninger 1978). Our analysis focuses on the diffusion of economic effects from rural to urban places. To sharpen our focus and simplify an already complex analysis, we, like Christaller, focus on trade in central place goods and assume a rigid one-way trade hierarchy.

Adoption of the rigid Christaller-like trade hierarchy has two important implications. First, it means that our model is not appropriate for estimating impacts to lower-order subregions from changes at higher-order subregions. The vehicle for transmitting these impacts is trade in noncentral place goods (specialized goods) from lower- to higher-order subregions. Trade in specialized goods is assumed away with a one-way trade hierarchy. The second implication of assuming one-way trade is an understatement, due to omitted feedback linkages, of the role of lower-order subregions in the economies of higher-order subregions.

Lower-order economic activity explains activity at a high-order subregion through the hierarchically downward flow of central place goods. To the extent that the higher-order subregion obtains specialized goods from the lower-order subregion, some of this economic effect will feed back to the lower-order subregion. This feedback in turn leads to another round of central place goods purchases, and thereby a second feedback, this time to the higher-order subregion. Two-way feedbacks continue, in the dampening fashion of expanded I-O multipliers, eventually approaching zero at both the lower- and higher-order subregion.

Feedbacks are omitted with one-way trade. As a result, impacts to the higherfrom the lower-order subregion are understated, as are impacts at the shock-initiating lower-order subregion. We recognize this understatement, but we are at the same time encouraged by the literature on interregional feedbacks indicating that these are likely small in magnitude (Miller 1966, 1969; Robison and Miller 1991). 


\section{EMPIRICAL SETTING FOR THIS STUDY: THE HIERARCHAL STRUCTURE OF THE SALT LAKE CITY AND IDAHO FALLS TRADE AREAS}

Influenced by central place theory and by the related notion of functional economic areas, the U.S. Department of Commerce, Bureau of Economic Analysis (BEA), mapped the principal trading areas of the U.S. economy (U.S. Department of Commerce 1975). BEA trade areas are centered on dominant trading cores and internally display relatively closed markets for labor and the business and consumer goods available there. Figure 1 presents the BEA's mapping of the Intermountain West. The veracity of the BEA's trade regions is reflected in television market areas as an indication of trade dominance. Southwestern Wyoming, for example, receives Salt Lake City television, and Teton County, Wyoming, receives Idaho Falls television.

The BEA's mapping of U.S. trade areas is limited by its implicit two-order core-periphery structure. For example, while Idaho Falls television availability corroborates the Idaho Falls trade area, Salt Lake City television also is available throughout the Idaho Falls trade area. Accordingly, it appears that the larger area exhibits a three-order trade hierarchy, with Salt Lake City at the top of the trade hierarchy, followed by Idaho Falls at the top of its own two-order trade hierarchy, followed by a collection of lowest-order peripheral subregions, either directly dominated by Salt Lake City or by both Salt Lake City and Idaho Falls.

Figure 2 presents our subregional breakdown of the Intermountain West's three-order trade hierarchy. In contrast to the intercommunity approach of Robison and Miller (1991), the broader geographic scope of this study dictates that we choose counties and multicounty areas as our minimum geographic units. Dark shaded multicounty areas in Figure 2 represent our regional trading cores. The "Salt Lake City core" includes Utah, Salt Lake, Davis, and Weber counties, Utah-a more or less continuous urban-suburban complex, locally known as the "Wasatch Front"-and Provo City, Salt Lake City, and Ogden City, Utah. The dark shaded area labeled "Idaho Falls core" includes Bannock, Bingham, Bonneville, Jefferson, and Madison counties, Idaho, an urban-suburban complex including the cities of Pocatello, Blackfoot, Idaho Falls, Rigby, and Rexburg, Idaho.

Peripheral subregions are in part segmented according to political boundaries. We also break an eight-county subregion, "Magic Valley," from what would otherwise be part of an unbroken Idaho Falls periphery. The Magic Valley subregion is centered on Twin Falls, Idaho. Magic Valley has its own television station, located in Twin Falls, and also receives Idaho Falls, Salt Lake City, and Boise, Idaho, television. Accordingly, we model Magic Valley as a separate sub- 
FIGURE 1

Economic and Political Boundaries of the Intermountain West

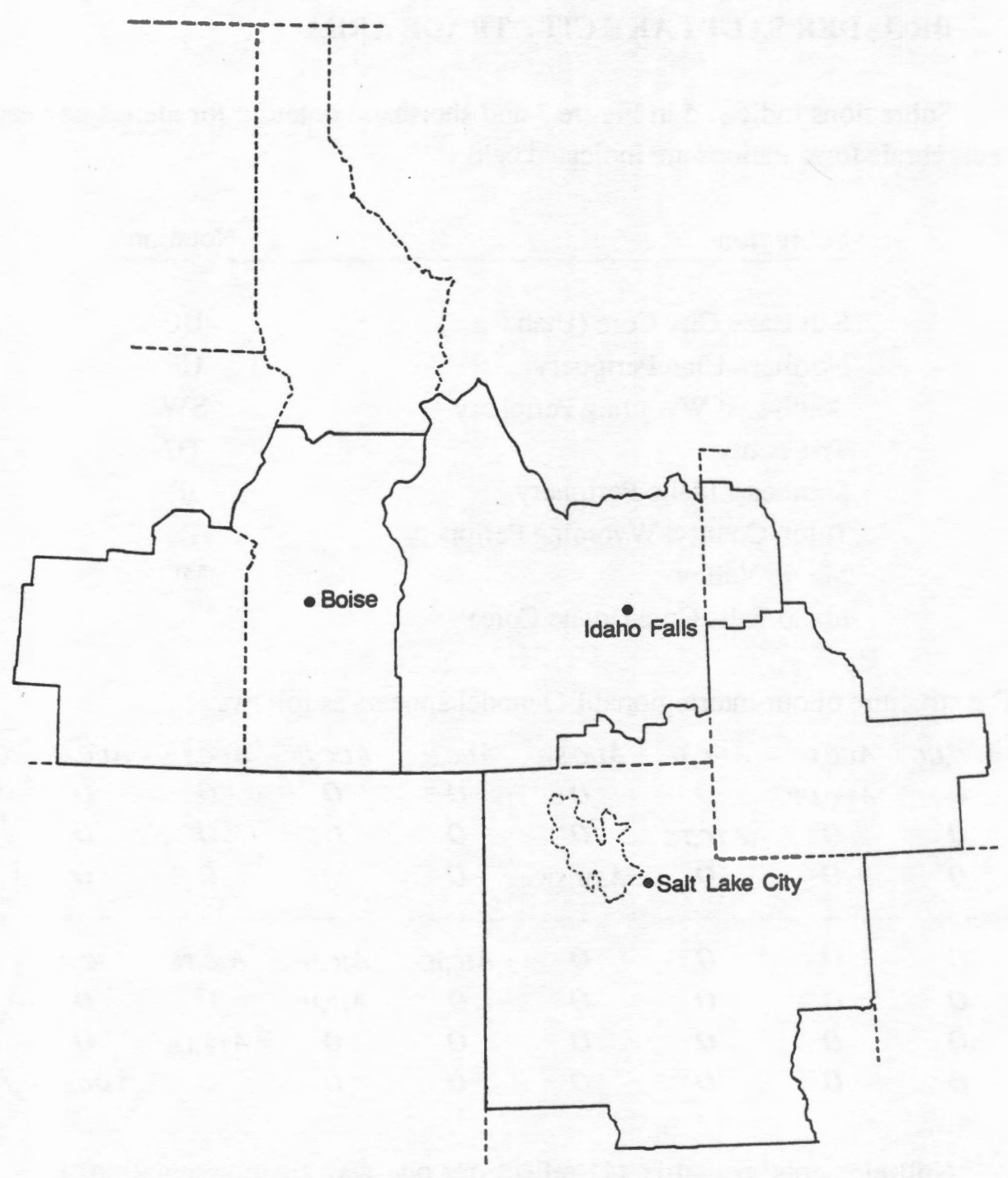


regional economy, occupying overlapping market shadows of Boise, Idaho Falls, and Salt Lake City.

\section{CONSTRUCTING AN INTERREGIONAL I-O MODEL FOR THE BROADER SALT LAKE CITY TRADE AREA}

Subregions indicated in Figure 2 and shorthand notation for identifying each in algebraic formulations are indicated below:

\begin{tabular}{lc} 
Subregion & Notation \\
\hline & \\
Salt Lake City Core (Utah Core) & UC \\
Northern Utah Periphery & UP \\
Southwest Wyoming Periphery & SW \\
TriCounty & TC \\
Southeast Idaho Periphery & IP \\
Teton County, Wyoming Periphery & TE \\
Magic Valley & MG \\
Idaho Falls Core (Idaho Core) & IC
\end{tabular}

The structure of our interregional I-O model appears as follows:

\begin{tabular}{|c|c|c|c|c|c|c|c|}
\hline$A \cup C, U C$ & $\boldsymbol{A} U C, U P$ & $A \cup C, T C$ & $A \cup C, S W$ & $A v C, I C$ & $A U C, I P$ & AUC,TE & $A U C, M G$ \\
\hline$O$ & $A U P, U P$ & $O$ & $O$ & 0 & $O$ & $O$ & $O$ \\
\hline 0 & $O$ & ATC,TC & $O$ & $O$ & 0 & 0 & $O$ \\
\hline$O$ & $O$ & $O$ & $A S W, S W$ & 0 & $O$ & 0 & $O$ \\
\hline$O$ & $O$ & 0 & 0 & $A_{I C, I C}$ & $A_{I C, I P}$ & $A_{I C, T E}$ & $A_{I C, M G}$ \\
\hline 0 & $O$ & $O$ & $O$ & 0 & $A_{I P, I P}$ & $O$ & $O$ \\
\hline$O$ & $O$ & $o$ & $O$ & $O$ & $O$ & $A T E, T E$ & 0 \\
\hline$O$ & 0 & 0 & 0 & 0 & $O$ & $o$ & $A_{M G, M G}$ \\
\hline
\end{tabular}

Null elements in matrix (1) reflect our one-way trade assumption. Intraregional trade appears on the principal diagonal interregional trade on the offdiagonal. The upper-left partition shows two-order trade in the BEA's Salt Lake City trade area, with the Salt Lake City core (UC) supplying all peripheral subregions, and otherwise no interregional trade either up the trade hierarchy or between same-order subregions. The lower-right partition shows similarly structured two-order trade in the BEA's Idaho Falls trade area. The upper-right partition of matrix (1) shows two-order trade between the Salt Lake City core and the Idaho 


\section{FIGURE 2}

Salt Lake City/ldaho Falls Trade Area

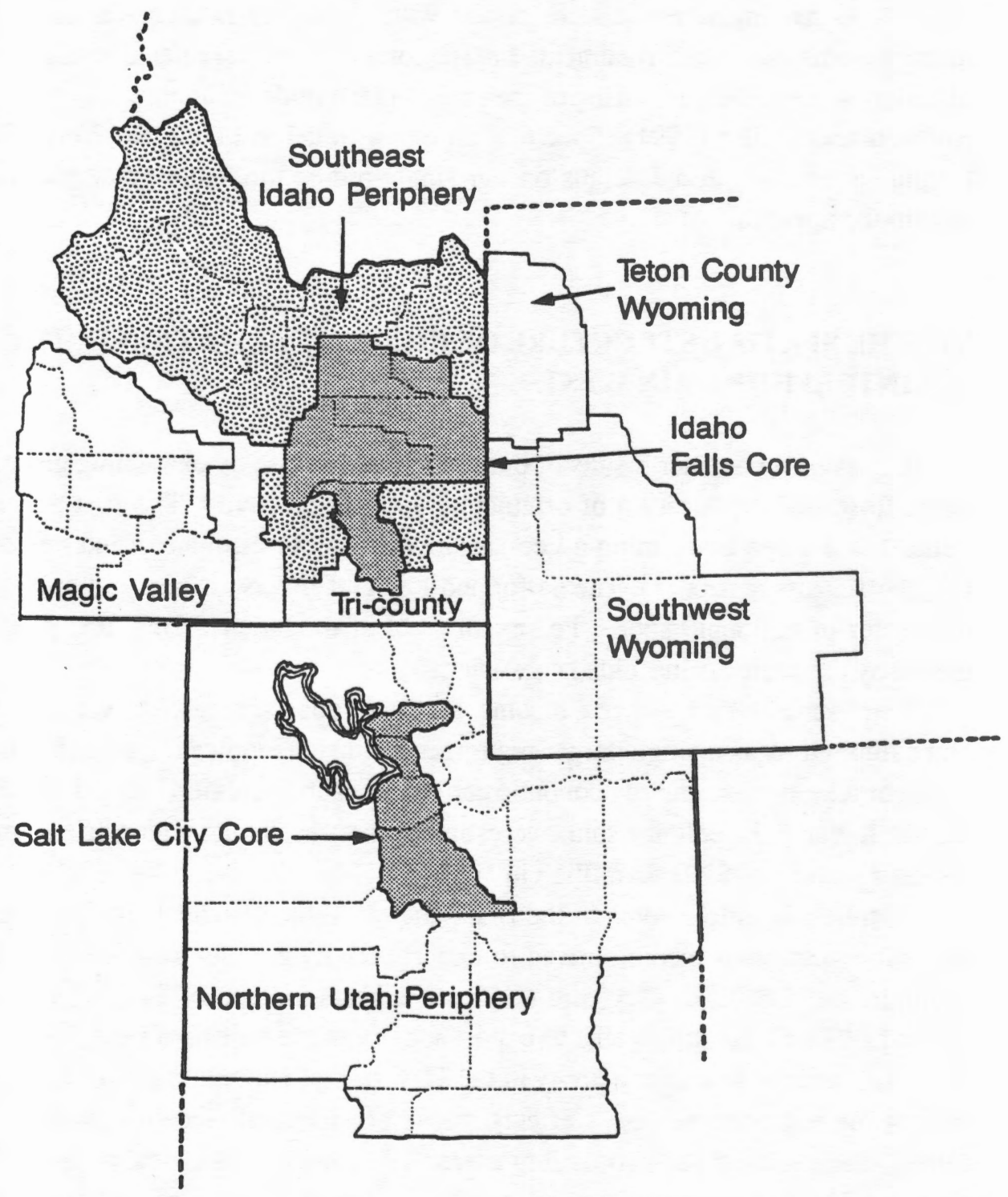


Falls core and three-order trade between the Salt Lake City core and the Idaho Falls peripheral subregions.

We constructed models for individual subregions with a standard singleregion supply-demand-pool (SDP) nonsurvey estimating procedure (Schaffer and Chu 1969). Our models are constructed to exhibit the economic base of subregions. Accordingly, models are closed with respect to households, state and local government, and investment. Interregional trade is estimated through application in a three-order setting of the central place trade-estimating technique of Robison and Miller (1991). Specifics on our adaptation of the Robison-Miller technique, and additional details on our single-region modeling procedures, appear in the appendix.

\section{THE SPATIAL STRUCTURE OF INCOME FORMATION IN THE INTERMOUNTAIN WEST}

Let us now consider results of our modeling exercise by examining gross income formation by location of originating economic activity. The first panel in Table 1 is derived by forming a Leontief inverse on our estimate of interregional I-O coefficients matrix (1). The so-formed Leontief inverse is post-multiplied by the vector of regional exports, i.e., exports out of the larger region, and premultiplied by the vector value added coefficients.

Row sums indicate gross income for individual subregions. Viewing the eight subregions as a single larger region, column sums indicate the contribution to larger region's income of economic activity in each subregion. As indicated by the far lower-right column sum, we estimate that the larger region has a gross regional income of \$29,086 million in 1987.

Individual cell elements in the first panel of Table 1 indicate the portion of row subregion gross income linked to export activity at column subregions. For example, the Salt Lake City core (UC) has a gross income of $\$ 17,597$ million, with $\$ 1,022$ million attributable to export activity in the Northem Utah Periphery (UP), $\$ 43$ million to export activity in the "TriCounty" subregion (TC), and so on. Except for neglected feedback effects, upper off-diagonal elements indicate the central place role of our two trading cores, Salt Lake City and Idaho Falls. Null elements in the lower off-diagonal reflect our one-way trade assumption. With unrestricted trade, export activity at our two trading cores would explain a portion of income in lower-order subregions.

The second panel of Table 1 indicates the relative dependence of row subregion income on activity at other subregions-first panel elements as a percent of first panel row sums. Given our one-way trade assumption, only the two trading 


\section{TABLE 1}

Intermountain West, Subregion Gross Income in 1987

by Location of Originating Economic Activity

\begin{tabular}{|c|c|c|c|c|c|c|c|c|c|}
\hline & \multicolumn{9}{|c|}{ (Minlions of 1987 Dollars) } \\
\hline & UC & UP & TC & SW & IC & IP & TE & MG & Sum \\
\hline UC & $\$ 15,301.7$ & $\$ 1,022.5$ & $\$ 42.7$ & $\$ 670.3$ & $\$ 73.5$ & $\$ 260.9$ & $\$ 45.5$ & $\$ 179.5$ & $\$ 17,596.6$ \\
\hline UP & & $\$ 3,608.5$ & & & & & & & $\$ 3,608.5$ \\
\hline TC & & & $\$ 125.1$ & & & & & & $\$ 125.1$ \\
\hline sw & & & & $\$ 1,910.3$ & & & & & $\$ 1,910.3$ \\
\hline IC & & & & & $\$ 1,898.6$ & $\$ 287.8$ & $\$ 42.8$ & $\$ 311.1$ & $\$ 2,540.3$ \\
\hline $\mathbb{I P}$ & & & & & & $\$ 1,016.3$ & & & $\$ 1,016.3$ \\
\hline $\mathrm{TE}$ & & & & & & & $\$ 270.5$ & & $\$ 270.5$ \\
\hline MG & & & & & & & & $\$ 2,018.0$ & $\$ 2,018.0$ \\
\hline Sum & $\$ 15,301.7$ & $\$ 4,631.0$ & $\$ 167.8$ & $\$ 2,580.6$ & $\$ 1,972.1$ & $\$ 1,565.0$ & $\$ 358.8$ & $\$ 2,508.6$ & $\$ 29,085.6$ \\
\hline
\end{tabular}

Percent of Subregion Gross Income

by Location of Originating Economic Activity

\begin{tabular}{lccccccccc} 
& UC & UP & TC & SW & IC & IP & TE & MG & Sum \\
\hline UC & 86.96 & 5.81 & 0.24 & 3.81 & 0.42 & 1.48 & 0.26 & 1.02 & 100.00 \\
UP & & 100.00 & & & & & & & 100.00 \\
TC & & & 100.00 & & & & & & 100.00 \\
SW & & & & 100.00 & & & & & 100.00 \\
IC & & & & & 74.74 & 11.33 & 1.68 & 12.25 & 100.00 \\
IP & & & & & & 100.00 & & & 100.00 \\
TE & & & & & & & 100.00 & & 100.00 \\
MG & & & & & & & & 100.00 & 100.00
\end{tabular}

Contribution to Regionwide Gross Income by Subregions

According to the Location of Income Generation

\begin{tabular}{llccccccc} 
& UC & UP & TC & SW & IC & IP & TE & MG \\
\hline UC & 100.00 & 22.08 & 25.45 & 25.97 & 3.73 & 16.67 & 12.68 & 7.16 \\
UP & & 77.92 & & & & & & \\
TC & & & 74.55 & & & & & \\
SW & & & & 74.03 & & & & \\
IC & & & & & 96.27 & 18.39 & 11.93 & 12.40 \\
IP & & & & & & 64.94 & & \\
TE & & & & & & & 75.39 & \\
MG & & & & & & & & 80.44 \\
Sum & 100.00 & 100.00 & 100.00 & 100.00 & 100.00 & 100.00 & 100.00 & 100.00 \\
\hline
\end{tabular}


cores exhibit such dependence. Subtracting principal diagonal percentages from 100 percent provides an indication of relative central place dependence. Accordingly, Idaho Falls depends on its role as a central place for approximately 25 percent $(\approx 100$ percent -74.74 percent) of its gross income, compared to 13 percent $(\approx 100$ percent -86.96 percent) for Salt Lake City. The Salt Lake City core has significant sources of specialized export income independent of its central place functions, Kennecott Copper and Hill Air Force Base, for example.

\section{CENTRAL PLACE DEPENDENCE AND INTERREGIONAL SPILLOVERS}

\section{Gross Subregional Income and Central Place Dependence}

It might be supposed that central place dependence varies directly with the income of dominated subregions, and the first and second panels of Table 1 exhibit instances in support of this thesis. For example, the roles of Magic Valley (MG) and the Teton County, Wyoming, periphery (TE) in the economy of the Idaho Falls core (IC) support the thesis. However, Table 1 also exhibits instances that contradict this thesis. For example, the roles of the Idaho Falls core (IC) and the southwest Wyoming periphery (SW) in the economy of the Salt Lake City core (UC) contradict the thesis.

In search of an explanation of central place dependence, let us turn our analysis from the perspective of the dominating subregions to that of the dominated subregions and examine factors determining spillovers from lower- to higher-order subregions. The third panel of Table 1 shows the spatial diffusion of economic effects from the perspective of lower-order subregions-first panel elements as a percent of first panel column sums. Off-diagonal elements show income spillovers up the trade hierarchy. For example, 35.06 percent ( $=18.39$ percent +16.67 percent $)$ of the broader regional contribution of export activity in the southeast Idaho periphery (IP) spills up the trade hierarchy to the Idaho Falls and Salt Lake City core subregions.

With the aid of Table 1's third panel, the seemingly contradictory roles of Idaho Falls (IC) and southwest Wyoming (SW) in the economy of the Salt Lake City core (UC) is explained by Idaho Falls' relatively small spillover to the Salt Lake City core-3.73 percent for the Idaho Falls core compared to 25.97 percent for the southwest Wyoming periphery. The remainder of our analysis of central place dependence focuses on the factors determining interregional spillovers. 


\section{Determinants of Interregional Spillovers}

While searching for the determinants of interregional spillovers, the regional I-O analyst and the central place theorist are apt to look at different things. Spillovers reflect interregional interconnectedness, and the regional I-O analyst is likely to look to interregional trade for an explanation. In contrast, the central place theorist is perhaps more likely to focus on intraregional interconnectedness for an explanation.

Given the structure of central place hierarchies, an inverse relationship can be predicted between hierarchical order and relative spillover. Hierarchical order mirrors the complexity of the commercial infrastructure. Lower-order subregions exhibit relatively undeveloped infrastructures and thus obtain a larger share of their consumer and business needs from higher-order subregions, resulting in greater spillovers. Intraregional interconnectedness provides a measure of infrastructure development in subregions.

Hamilton and Jensen (1983) examine a number of summary measures of interconnectedness in single region I-O models. We adapted two of Hamilton and Jensen's measures, the "mean of intermediate coefficient columns sums" and "the percentage of intermediate transactions," to examine interconnectedness in the context of our interregional model.

Consider first the mean of interregional coefficient column sums. For the southeast Idaho peripheral subregion (IP), for example, we compute the mean of interregional coefficient column sums as follows:

$$
\{(1) A U C, I P+(1) \text { AIC,IP }\}[1] \frac{1}{n}
$$

where (1) and [ 1 ] are sum vectors, and $n$ is the number of sectors in the (IP) model.

Table 2 lists spillovers and measures of interconnectedness for our eight subregions. Column 1 lists spillovers arranged in descending order. Column 2 lists the mean of interregional coefficient column sums arranged in descending order. The theory behind a comparison of columns 1 and 2 is that of the regional I-O analyst, which explains that relative spillover is explained by interregional interconnectedness. Columns 1 and 2 yield a Spearman rank correlation of .73810, indicating a less than perfect explanation of spillovers.

While the mean of interregional coefficient column sums provides a measure of interregional interconnectedness, there is no weighting of interregional trade according to the relative output of the lower-order subregion industries that generate the gross trade flows. "The percentage interregional transactions" captures these weighting effects. For the southeast Idaho peripheral economy (IP), for example, we compute percentage of interregional transactions as follows: 
TABLE 2

Intermountain West Subregions Ranked According to Relative Spillovers and Selected Measures of Intraand Interregional Interconnectedness

\begin{tabular}{|c|c|c|c|c|c|c|c|c|c|}
\hline \multicolumn{2}{|c|}{$\begin{array}{c}\text { Relative } \\
\text { Spillovers } \\
\text { (1) }\end{array}$} & \multicolumn{2}{|c|}{$\begin{array}{l}\text { Mean } \\
\text { Interregional } \\
\text { Coefficient } \\
\text { Sums } \\
\text { (2) } \\
\end{array}$} & \multicolumn{2}{|c|}{$\begin{array}{c}\text { Percentage } \\
\text { Interregional } \\
\text { Transactions } \\
\text { (3) } \\
\end{array}$} & \multicolumn{2}{|c|}{$\begin{array}{c}\text { Mean } \\
\text { Intermediate } \\
\text { Coefficient } \\
\text { Sums } \\
(4)\end{array}$} & \multicolumn{2}{|c|}{$\begin{array}{c}\text { Percentage } \\
\text { Intermediate } \\
\text { Transactions } \\
\text { (5) }\end{array}$} \\
\hline IP & 35.06 & IP & .13189 & IP & 14.17 & SW & .43321 & IP & 44.20 \\
\hline SW & 25.97 & sw & .11310 & sw & 11.02 & IP & .44099 & sw & 46.06 \\
\hline TC & 25.45 & TE & .11093 & TE & 9.92 & $\mathrm{TE}$ & .53698 & TC & 52.75 \\
\hline TE & 24.61 & MG & .08478 & TC & 9.71 & TC & .54135 & TE & 57.84 \\
\hline UP & 22.08 & UP & .06078 & UP & 7.07 & MG & .54509 & UP & 58.61 \\
\hline MG & 19.56 & IC & .05054 & MG & 6.50 & UP & .56140 & MG & 60.61 \\
\hline IC & 3.73 & TC & .04590 & IC & 3.70 & IC & .57018 & IC & 65.29 \\
\hline UC & 0.00 & UC & .0 & UC & 0 & UC & .64282 & UC & 71.89 \\
\hline \multicolumn{2}{|c|}{$\begin{array}{l}\text { Rank Correlatior } \\
\text { Relative to } \\
\text { Column (1): }\end{array}$} & \multicolumn{2}{|c|}{.73810} & \multicolumn{2}{|c|}{.97619} & \multicolumn{2}{|c|}{.92857} & \multicolumn{2}{|c|}{1.0} \\
\hline
\end{tabular}

$$
100 *\left\{(1) \text { AUC,IP } X_{I P}+(1) A_{I C, I P} X_{I P}\right\} /(1) X_{I P}
$$

Column 3 of Table 2 presents the percentage of interregional transactions. Comparison with column 1 indicates considerable improvement over the unweighted mean of interregional coefficient column sums (column 2). Note that only subregions TE and TC are transposed. Columns 1 and 3 yield a Spearman rank correlation of .97619 .

Let us now turn to the explanation of spillovers favored by the central place theorist, i.e., relative spillovers explained by the commercial infrastructure development in lower-order subregions. We start with "the mean of intermediate coefficient column sums." For our southeastern Idaho peripheral economy (IP), for example, we compute the mean of intermediate coefficient column sums as follows:

$$
\text { ( } 1 \text { ) AIP,IP [ } 1 \text { ] } \frac{1}{n}
$$

where again, $\mathrm{n}$ is the number of sectors in the IP model.

Column 4 of Table 2 presents the mean of intermediate coefficient column sums arranged in ascending order, a low mean indicating a less developed commercial infrastructure, and therefore greater spillovers through provision of goods from higher-order subregions. While comparison of columns 1 and 4 indicates several transpositions, movements in rank are small. Columns 1 and 4 yield a rank 
correlation of .92857 , a considerable improvement over column 2's mean of interregional coefficient columns sums, though a somewhat poorer performance than column 3's percentage of interregional transactions.

Finally, we compute the percentage of intermediate transactions. For our IP model, for example, the percentage of intermediate transactions is computed as follows:

\section{$100 *(1) A_{I P, I P} X_{I P} /(1) X_{I P}$}

Column 5 of Table 2 presents the percentage of intermediate transactions for our eight subregions. Comparison with column 1 indicates a perfect match-rank correlation of 1.0.

Our analysis of central place dependence and spillovers is based on summary measures of interconnectedness and a simple statistical analysis. Nonetheless, it does highlight an important feature of hierarchically structured regions, namely, that the degree of infrastructure development at lower-order subregions is a key determinant in the spatial diffusion of economic effects. This finding has important implications for economic impact assessment and regional economic development policy.

\section{DISCUSSION AND CONCLUSIONS}

The spatial diffusion of economic effects is an important issue in regional economic analysis. Introducing the spatial dimension in I-O analysis substantially increases the complexity of the modeling task, which has forced us to take a number of shortcuts. In particular, our subregions are drawn broadly, in the coreperiphery sense of functional economic areas, rather than as individual settlements, in the punctiform-region sense of central place theory. We have also chosen to limit our analysis of trade to a rigid one-way structure. This latter limitation means that our model is only applicable to development and impact issues involving economic effects from lower- to higher-order subregions, and even then impacts are biased downward due to neglected feedback effects.

These limitations notwithstanding, our analysis does permit us to draw at least two prominent conclusions unavailable from single-region I-O models and from interregional I-O models constructed on other than central place principles. One conclusion has implications for regional economic impact assessment, the other for regional economic development policy.

The context of regional economic impact assessment is one where a change in one part of the economy engenders changes in other parts of the economy. Our 
analysis focuses on changes originating in lower-order subregions. We find that the spatial diffusion of impacts depends on the degree of economic infrastructure development at the shock-initiating subregion and on the infrastructure development of subregions along the hierarchical path to the impact-terminating highestorder subregion. In general, impacts to higher-order subregions are less as the economic development of the shock-initiating subregions are greater, or as economically developed subregions intervene along the hierarchical path.

The context of regional economic development is one where funds are targeted to meet prescribed economic development objectives. The effectiveness of development initiatives is enhanced by knowledge of the spatial diffusion of benefits. In some cases, the priorities of the economic development authority may be best attained by targeting otherwise lower-priority subregions. For example, the most effective means for revitalizing communities with existing or potential trade dominance may be to encourage expansion in the economic base of the dominated hinterland. In addition, spillover benefits to still higher-order places might be identified and incorporated in the decision calculus as well.

In a related context, economic development policies often aim at inducing threshold and import substitution effects, thereby deepening the economic infrastructure of targeted regions. Though there are hazards in drawing too deep an inference from a static model with fixed commercial and personal consumption propensities, our analysis suggests that as lower-order infrastructure development proceeds, spillovers will decline, implying more rapid growth over time at loweras opposed to higher-order subregions. With constant consumption propensities, and absent independent growth in higher-order subregions, we might expect an overall leveling effect from lower-order subregion development.

Improvements in transportation and communications and technological change in agriculture and other predominantly extractive rural industries have led to greater spatial concentration in many rural regions. At the same time, however, other rural regions have grown and deepened their infrastructure, thus lessening their dependence on larger regions. Our analysis helps explain these countervailing trends and provides a framework where economic development policies, aimed at differential growth targets between subregions, can be appropriately framed.

\section{APPENDIX: MODELING PROCEDURES}

\section{Estimating I-O Coefficients for Individual Subregions}

We estimated intraregional I-O coefficients with a mixed four- and two-digit SIC level of detail and borrowed 1977 U.S. national model coefficients (U.S. 
Department of Commerce, Bureau of Economic Analysis 1979). National coefficients were regionalized through a standard SDP nonsurvey application (Schaffer and Chu 1969).

Our models are constructed to convey a 1987 base year. County employment data for sectors other than agriculture are from 1984 County Business Patterns obtained from Resource Economics and Management Analysis (1987) in a disclosure-unsuppressed form and bridged to the 537 industry/commodity detail of the 1977 national I-O model. These data are updated to 1987 by controlling to Utah, Idaho, and Wyoming Job Service estimates published at roughly the twodigit SIC level. Revenues for agricultural sectors are obtained directly from the 1987 Census of Agriculture (U.S. Department of Commerce, Bureau of the Census 1989). Revenues for nonagricultural sectors are estimated as the product of employment and national sales-employment ratios (Yuskavage 1985).

Our analysis hinges on portraying central place functions as a component of the economic base of subregions, which requires that we close our subregion models in a manner consistent with the economic base model, i.e., closed with respect to households, state and local government, and investment (see, for example, Hirsch 1973, 206). We borrowed consumption, state and local government, and investment column coefficients from the national I-O model. Row coefficients for these same sectors are obtained as national value added coefficients, scaled to yield regional personal consumption expenditures, state and local government revenues, and regional investment.

In light of recent observations on model closure, particularly by Rose and Stevens (1991), we recognize that even in models closed in the economic base fashion, not all consumption, state and local government spending, and investment is endogenous. Accordingly, we left a portion of consumption exogenous, based on assumptions regarding published eamings and other components of personal income in regions (U.S. Department of Commerce, Bureau of Economic Analysis 1990), and we left a portion of state and local government revenues exogenous, based on the federal government's share in state and local govemment expenditures (U.S. Department of Commerce, Bureau of the Census 1987). Exogenous investment proved more problematic. We estimated gross regional investment simply as each region's share (determined by its share of national employment) of national gross private fixed domestic investment as indicated in the national I-O model (U.S. Department of Commerce, Bureau of Economic Analysis 1979). Of this, we arbitrarily assume 25 percent as exogenous. Sensitivity testing on this assumption indicated little impact on the analytic findings reported in this paper. 
Nonsurvey Technique for Estimating Interregional I-O Coefficients

Robison and Miller (1991) extended the SDP technique beyond the singleregion setting to interregional trade in a central place hierarchy. We present a brief outline of the technique's mathematics here and details on its specific application in our empirical modeling exercise in the next section. In our final appendix section, we briefly address the reasonableness of the Robison-Miller approach for estimating interregional trade in our Intermountain West hierarchically structured region.

Consider a simple core-periphery trade hierarchy, i.e., a dominant trading core $\mathrm{C}$ and a dominated peripheral subregion $\mathrm{P}$. Let $\mathrm{NCP}$ be an array of borrowed (e.g., national model) I-O coefficients with the row and column structure of ACP, the core to periphery interregional I-O coefficients matrix. Let $\mathrm{HCP}_{\mathrm{CP}}$ be an array of 1s and Os that map elements of APP into the row and column structure of ACP.

The key to the Robison-Miller technique is formation of a "gross import requirements matrix," GCP, with coefficients indicating the demand by the peripheral subregion for commodities produced in the core in excess of that satisfied by peripheral subregion industries. Assuming borrowed technology, an estimate of GCP is obtained as follows:

\section{$\mathbf{G} C P=\left\{N_{C P}-H_{C P A P P}\right\}$}

Next let $R_{C P}$ be a column vector indicating the import demand by the peripheral subregion for commodities produced in the core estimated as follows:

$$
\mathbf{R} C P=\mathbf{G C P}_{\mathbf{P}} \mathbf{X}_{\mathbf{P}}
$$

where $\mathbf{X}_{\mathbf{P}}$ is the total gross output vector for the peripheral subregion. Vector (A3) serves to form scalars:

$$
\rho_{C P_{i}}=\begin{aligned}
& E_{C_{i}} / R_{C P_{i}} \text { if } E_{C_{i}}<R_{C P_{i}} \\
& 1.0 \text { otherwise }
\end{aligned}
$$

where $\mathrm{EC}_{\mathrm{i}}$ is exports of commodity i from the core. Arrayed in a diagonal matrix, scalars (A3) premultiply (A1), yielding an estimate of interregional I-O coefficients thus:

$$
A_{C P}=\left\{\hat{\rho}_{C P}\right\} G_{C P}
$$


Estimating Interregional I-O Coefficients in the Intermountain West Trade Region

Interregional I-O coefficient matrices for the Salt Lake City trade area appearing in the upper-left partition of matrix (1) are estimated through formation of the following "gross import requirements matrices":

$$
\begin{aligned}
& \text { Guc,UP }=\text { \{Nuc,UP }- \text { Huc,UPAUP,UP } \\
& \text { Guc,TC }=\text { \{Nuc,TC }- \text { Huc,TCATC,TC }\} \\
& \text { Guc,sw }=\text { \{Nuc,sw }- \text { Huc,SwAsw,Sw }
\end{aligned}
$$

Interregional coefficient matrices for the Idaho Falls trade area appear in the lower-right partition of matrix (1). Magic Valley is viewed as a subregional economy in the overlapping market reach of Boise, Idaho Falls, and Salt Lake City. We treat these three directions of dominance in an asymmetric fashion, assuming Magic Valley satisfies its import demands from Idaho Falls and Boise first, an instance of two-order trade dominance, and then from Salt Lake City, an instance of three-order trade dominance.

Trade between Boise and Magic Valley is summarized in an interregional I-O coefficients matrix ABO,MG not shown in (1). Interregional I-O coefficient matrices for the Idaho Falls trade area are estimated with the following gross import requirements matrices:

$$
\begin{aligned}
& \text { GIC,IP }=\{\text { NIC,IP }- \text { HIC,IPAIP,IP }\} \\
& \text { GIC,TE }=\{\text { NIC,TE }- \text { HIC,TEATE,TE }\} \\
& \text { GIC,MG }=\text { \{NIC,MG }- \text { HIC,MGAMG,MG }- \text { HIC,BOABO,MG }\}
\end{aligned}
$$

We are left with interregional coefficient matrices appearing in the upperright partition of (1), reflecting Salt Lake City's dominance of the Idaho Falls trade area. These are estimated according to the procedure presented above with the following gross import requirements matrices:

$$
\begin{aligned}
& \text { GUC,IC }=\{\text { NUC,IC }- \text { HUC,ICAIC,IC }\} \\
& \text { GUC,IP }=\{\text { NUC,IP }- \text { HUC,IPAIP,IP }- \text { HUC,ICAIC,IP }\} \\
& \text { GUC,TE }=\{\text { NUC,TE }- \text { HUC,TEATE,TE }- \text { HUC,ICAIC,TE }\} \\
& \text { GUC,MG }=\{\text { NUC,MG - HUC,MGAMG,MG-HUC,ICAIC,MG-HUC,BOABO,MG }\}
\end{aligned}
$$




\section{Reasonableness of Our Interregional Trade Estimates}

Our interregional trade estimates are based on a three-order extension of the two-order procedure introduced by Robison and Miller (1991). The RobisonMiller technique is in turn a spatial variation of the standard single-region SDP technique, with similarities in approach to the Harvard Economic Research Project's multiregional input-output (MRIO) model (Polenske 1980). Like the MRIO approach, the Robison-Miller technique estimates interregional I-O coefficients through proportional adjustments of national coefficients across industries in the destination region. The MRIO approach bases its adjustments on externally gathered data on gross interregional commodity shipments (Rodgers 1973), while the Robison-Miller approach estimates gross interregional shipments internally, based on assumptions regarding the hierarchical structure of trade and a spatial extension of the SDP logic.

The standard SDP technique assumes regional demands are satisfied from regional supplies with only excess supplies being exported. The technique thereby assumes maximum intraregional trade and no crosshauling. With clear parallels, the Robison-Miller interregional trade estimating technique assumes excess demands in dominated subregions are satisfied from excess supplies in dominating subregions. The technique thus assumes maximum trade between dominating and dominated subregions and no crosshauling either between subregions or with the outside world.

It has been argued that the maximum intraregional trade assumption of the SDP technique is reasonable, provided the region is in some sense a functional economic area, i.e., provided the region exhibits some degree of market closure for labor and other business and consumer goods and services (Robison and Miller 1988). Likewise, the maximum trade assumption in the interregional context appears reasonable, provided the larger region exhibits some degree of closure, i.e., provided the larger region is in some sense a functional economic area.

This paper models the functional economic area dominated by the Salt Lake City trading core. To the extent that our specification of that economic area, and the functional economic subregions within that area, is accurate, our application of the spatial extension of the SDP technique should provide reasonable results.

\section{REFERENCES}

Berry, Brian J. L., John B. Parr, Bart J. Epstein, Avijit Ghosh, and Robert H. T. Smith. Market Centers and Retail Location. Theory and Applications. Englewood Cliffs, N.J.: Prentice Hall, 1988. 
Christaller, Walter. Central Places in Southern Germany. Translated by C. W. Baskins. Englewood Cliffs, N.J.: Prentice Hall, 1966.

Fox, Karl A., and Krishna Kumar. "The Functional Economic Area: Delineation and Implications for Economic Analysis and Policy." Papers of Regional Science Association 15 (1965): 57-85.

Hamilton, Joel R., and Rodney C. Jensen. "Summary Measures of Interconnectedness for Input-Output Models." Environment and Planning A 15 (1983): 55-65.

Hirsch, Wemer Z. Urban Economic Analysis. New York: McGraw-Hill, 1973.

Isard, Walter. "Interregional and Regional Input-Output Analysis: A Model of a Space Economy." Review of Economic Statistics 33 (1951): 318-328.

Lossch, August. "The Nature of Economic Regions." Southern Economic Journal 5 (1938): 71-78.

Miller, Ronald E. "Interregional Feedback Effects in Input-Output Models: Some Preliminary Results." Papers of the Regional Science Association 17 (1966): 105-125.

. "Interregional Feedbacks in Input-Output Models: Some Experimental Results." Western Economic Journal 7 (1969): 41-50.

Mulligan, Gordon F. "Additional Properties of a Hierarchical City-Size Model." Journal of Regional Science 19, no. 1(1979): 57-66.

Parr, John B. "Interaction in an Urban System: Aspects of Trade and Commuting." Economic Geography 63, no. 3 (1987): 223-240.

Polenske, Karen R. The United States Multiregional Input-Output Accounts and Model. Lexington, Mass.: D.C. Heath, 1980.

Resource Economics and Management Analysis. 1984 County Business Patterns for Idaho, Wyoming, and Utah in a disclosure-unsuppressed form bridged to the 537 industry/commodity detail of the 1977 national input-output model. Unpublished data files, 1987.

Robison, M. Henry, and Jon R. Miller. "Cross-Hauling and Non-Survey Input-Output Models: Some Lessons from Small-Area Timber Economies." Environment and Planning A 20 (1988): 1523-1530.

. "Central Place Theory and Intercommunity Input-Output Analysis."

Papers in Regional Science 70, no. 4 (1991): 399-417.

Rodgers, John M. State Estimates of Interregional Commodity Trade. Lexington, Mass.: Lexington Books, 1973.

Rose, Adam Z., and Benjamin H. Stevens. "Transboundary Income and Expenditure Flows in Regional Input-Output Models." Journal of Regional Science 31, no. 3 (1991): 253-272. 
Schaffer, William A., and Kong Chu. "Nonsurvey Techniques for Constructing Regional Interindustry Models." Papers of the Regional Science Association 23 (1969): 83-101.

Seninger, Stephen F. "Expenditure Diffusion in Central Place Hierarchies: Regional Policy and Planning Aspects." Journal of Regional Science 18 (1978): 243-261.

U.S. Department of Commerce, Bureau of the Census. "1987 Census of Governments." Government Finances 4, no. 5 (1987). . "Census of Agriculture." Computer tapes for census year 1987 (1989).

U.S. Department of Commerce, Bureau of Economic Analysis. The Detailed Input-Output Structure of the U.S. Economy: 1972. Washington, D.C., 1979. Local Area Personal Income, Volume 5, Southwest Rocky Mountain and Far West Regions. Washington, D.C., 1990.

U.S. Department of Commerce, Bureau of Economic Analysis, Regional Economic Analysis Division. "The BEA Economic Areas: Structural Changes and Growth, 1950-73." Survey of Current Business (1975): 14-25.

Yuskavage, Robert E. "Employment and Employee Compensation in the 1977 Input-Output Accounts." Survey of Current Business 65 (1985): 11-20. 